\title{
Simulation of reflow-based heat transfer on different thermocouple constructions
}

\author{
Dániel Straubinger, Balázs Illés, Richárd Berényi, Attila Géczy \\ Budapest University of Technology and Economics, Department of Electronics Technology, Budapest, Hungary, \\ daniel.straubinger@ett.bme.hu
}

\begin{abstract}
In this paper, the heating during reflow soldering for different thermocouple constructions is modelled in order to reveal possible deviations originated from thermocouple constructions. K-type (Chromel-Alumel) thermocouples are investigated from the aspect of various physical constructions. The physical dimensions were measured with optical microscopy for several types of thermocouples. Based on those results, CAD geometry was realized for finite element analysis. The temperature dependence of the welded hot-spot was investigated in time domain with different uninsulated wire lengths close to the hot-spot, insulation- and hot-spot radiuses. The effect of the various heat transfer coefficient values was also analyzed. The simulation results were also compared with validation measurements performed with a K-type thermocouple in a Vapour Phase Soldering (VPS) chamber.
\end{abstract}

\section{INTRODUCTION}

Reflow soldering technology demands a narrow process window in most cases regarding the reflow temperature profile. For maintaining the proper heating gradients, it is necessary to measure the temperature of the board, the different types of components and solder joints. For those purposes, widely available thermocouples are used in electronics manufacturing due to their low cost and reliability. The are several factors affecting measurement accuracy. Different types such as K, J, T, N, etc. are available with different physical dimensions adapting for various applications and temperature ranges. Their working principle is based on the Seebeck-effect (thermoelectric effect): as the hot-spot is heated, the potential difference proportional to the temperature can be measured between the cold junction and the hot-spot.

Mounting the thermocouples to a printed circuit board (PCB) can be performed in several different ways. The most generally used techniques are adhesive epoxy glue, high-temperature melting point solder alloy, heat resistant polyimide tape and aluminium tape. The optimal attachments method may differ due to the different reflow soldering technologies. H. Shaukatullah et al. compared different types of attachments methods including polyimide tape, aluminium tape and silver plus insulating epoxy measuring a plastic quad flat pack (PQFP) thermal characteristics with several different types of thermocouples having different gauge sizes [1]. However, in the field of reflow soldering, the soldering environment determines the optimal choice of attachment, because the heat transfer is different in case of infrared-, convection- or a vapour phase soldering oven. During the process, the exposed wire of the thermocouples are also heated, therefor they can affect the temperature of the hot-spot. For fine wire thermocouples, Papaioannou et al. showed that conduction error can be significant [2]. Noriega et al. showed that as the non-insulated length gets longer, the error in the repeatability of the measurements is also increased [3].

Thermocouple constructions offer a different solution on the insulation side, also enabling price and physical construction categories for various applications. For general purpose in reflow soldering a few examples are presented: PFA, PTFE or glass fibre insulated thermocouples can be used in such ovens with the condition of the maximum allowed temperature on the insulation [4]. 
In this paper, we aim for a better understanding on how these thermocouples work, in related to the construction, and within the application field of reflow soldering. While previous works mention the effect of uninsulated thermocouple wires near the hot spot [5] or the impact of a larger hot spot or overall thermal mass of the construction [6], we try to investigate the possible differences which can lead to optimal sensor application, more precise validation results in reflow process modelling, and overall, better profiling - resulting in optimized reflow soldering.

\section{MATERials AND MODElS}

\subsection{Thermocouple dimensions and materials}

The proposed geometry is based on a selected commercially available $\mathrm{K}$ type thermocouple. The relevant dimensions of the thermocouple were measured via optical microscopy (Olympus BX51) including the diameter of the welded hot-spot, cable diameter without insulation and the diameter of the insulation.

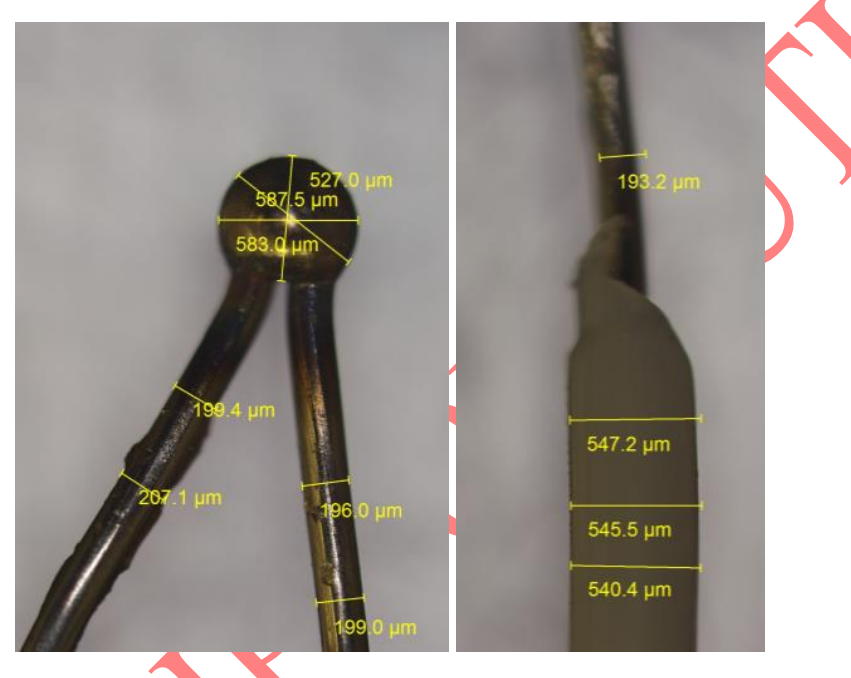

Fig. 1. K type thermocouple dimension measurement

K type thermocouples use Chromel (nickel, chromium) and Alumel (nickel, aluminium, manganese, silicon) alloys as the material of two wires. Perfluoroalkoxy Alkane (PFA) is used in this study as the insulation material on the wires.

Table 1. contains the material properties used during the simulation of the heat transfer [7].

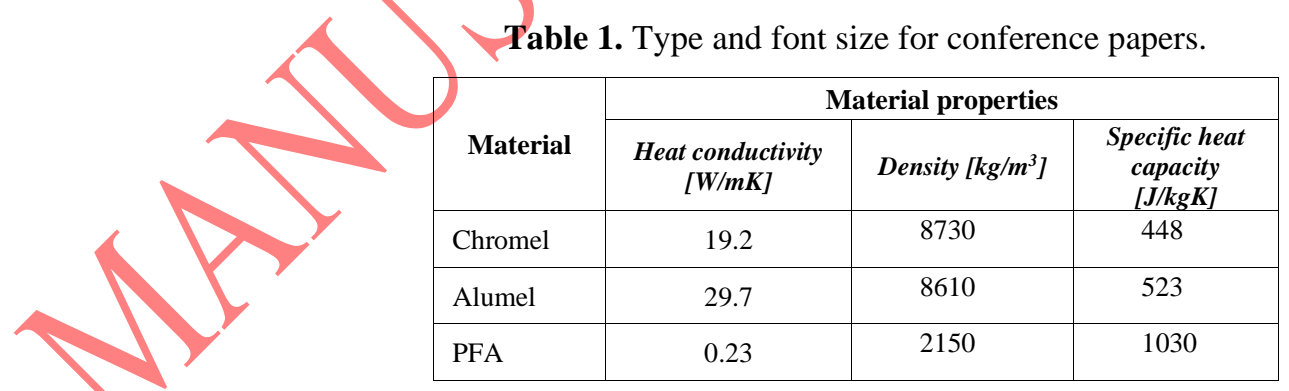

Based on the aforementioned design and properties, a CAD model was constructed. The model consists of an Alumel and a Chromel wire with a welded hot-spot. The hot-spot uses a combined material of the wires (composite). The density, heat conductivity and the specific heat capacity of the hot-spot (hs) are calculated with the values of Table I. as follows (Eq. 1). 


$$
\rho_{\text {hs }}=\frac{\rho_{\text {Alumel }}+\rho_{\text {Chromel }}}{2}
$$

Where $\rho_{h s}$ is the density of the composite material (hot-spot), $\rho_{\text {Alumel }}$ and $\rho_{\text {Chromel }}$ are the densities of the Alumel and Chromel wires, respectively. The heat conductivity $\left(k_{h s}\right)$ and specific heat capacity $\left(c_{h s}\right)$ is calculated proportionally to the masses of the materials.

$$
\begin{aligned}
k_{h s} & =k_{A l u} \frac{\rho_{A l u}}{\rho_{A l u}+\rho_{C h r}}+k_{C h r} \frac{\rho_{\text {Chr }}}{\rho_{\text {Alu }}+\rho_{\text {Chr }}} \\
c_{\text {hs }} & =c_{\text {Alu }} \frac{\rho_{\text {Alu }}}{\rho_{\text {Alu }}+\rho_{\text {Chr }}}+c_{\text {Chr }} \frac{\rho_{\text {Chr }}}{\rho_{A l u}+\rho_{C h r}}
\end{aligned}
$$

\subsection{Simulation model}

The CAD geometry was created in a way that different geometry variations can be easily simulated. The main parameters used for the simulation are the radius of the hot-spot, the radius of the insulation on the wire, and the bare cable length (directly from the length of insulation). The basic realization can be seen in Fig. 2. Usually, the length of a thermocouple is over $1 \mathrm{~m}$, we focus only on the welded end of the wire. On each side, the wires are $11.57 \mathrm{~mm}$ long (10 $\mathrm{mm}$ long straight wire up to the curvature).

0

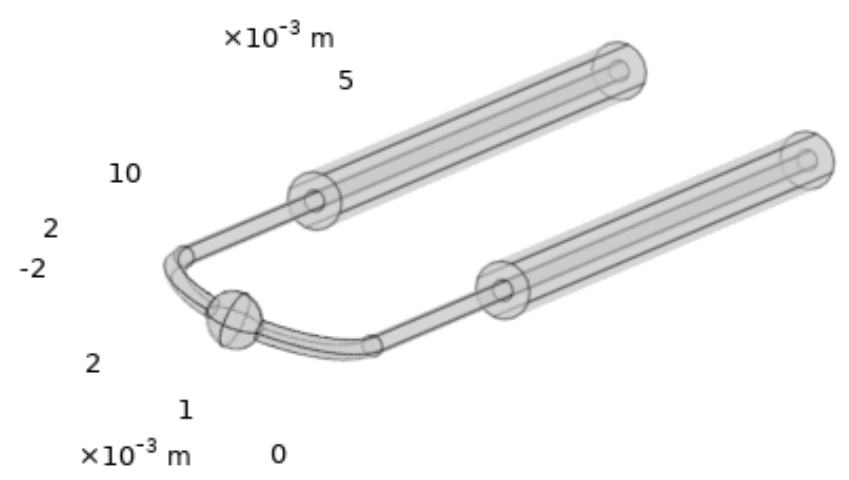

Fig. 2. CAD model (270 $\mu \mathrm{m}$ radius hot spot, $270 \mu \mathrm{m}$ radius insulation, $7 \mathrm{~mm}$ insulation length)

In case of VPS, the heat is transferred to the structure via the condensed Galden layer on the surface. For the modelling, a heat transfer coefficient is realized, which described the soldering. Table II. contains the different cases of the simulation. The thermocouple constructions usually vary and also wear during frequent laboratory usage. The aim of the simulation is to have information regarding the effect of different realizations on the heat transient of the hot-spot.

Table 1I. Different modelling parameters

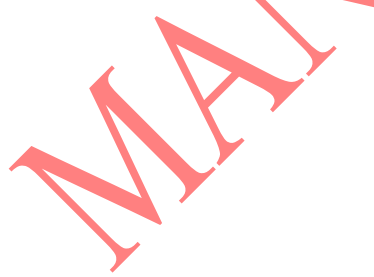

\begin{tabular}{|c|c|c|}
\hline \multicolumn{3}{|c|}{ Simulation cases } \\
\hline $\begin{array}{c}\text { Insulation length } \\
{[\mathbf{m m}]}\end{array}$ & $\begin{array}{c}\text { Insulation } \\
\text { thickness }[\boldsymbol{\mu m}]\end{array}$ & $\begin{array}{c}\text { Hot-spot radius } \\
{[\boldsymbol{\mu m}]}\end{array}$ \\
\hline $\begin{array}{c}\text { from 2 to 10 with } \\
\text { a step size of 1 }\end{array}$ & 270,400 & 270,400 \\
\hline
\end{tabular}

All the combinations result in 36 different simulation cases. Insulation length is measured from the end of the wires.

The simulation was performed using finite element method. A heat flux boundary condition was set to the surfaces, with a heat transfer coefficient of $60\left[\mathrm{~W} / \mathrm{m}^{2} \mathrm{~K}\right]$ to represent convection based reflow heating [8], and 210 $\left[\mathrm{W} / \mathrm{m}^{2} \mathrm{~K}\right]$ and $420\left[\mathrm{~W} / \mathrm{m}^{2} \mathrm{~K}\right]$ for vapour phase soldering. The heat transfer coefficient for vapour phase soldering was chosen according to a practical value (considerably higher than the coefficient reported for convection); the 
coefficient for VPS was reported to be between 90 and up to several hundred $\mathrm{W} / \mathrm{m}^{2} \mathrm{~K}[9,10]$ in different setups and process settings. The maximum temperature is $170-180{ }^{\circ} \mathrm{C}$ in this particular case (depending on actual state and temperature offset of Galden), to represent low-temperature reflow with Galden HT170 (due to the boiling point drift of our validation environment), which is in focus for our experiments and VPS related projects. The method is transferable for higher temperature Galden for traditional lead-free temperatures. It is suggested that the current results will be more emphasized in higher temperature conditions.

Heat flux boundary condition was set to describe the heat transfer (Eq. 4):

$$
q_{0}=h\left(T_{\text {ext }}-T\right)
$$

where $q_{0}$ is the inward heat flux $\left[\frac{\mathrm{W}}{\mathrm{m}^{2}}\right]$ (normal to the boundary), $T_{\text {ext }}$ is the temperature of the boiling point of the Galden (the temperature to which the thermocouple heats) and the physics is described within the $h$ heat transfer coefficient $\left[\frac{\mathrm{W}}{\mathrm{m}^{2} \mathrm{~K}}\right], T$ is the temperature of a point of the body. The initial temperature condition of the body is (Eq. 5):

$$
T_{0}=293.15 \mathrm{~K}
$$

The end of the wires was set to a boundary condition of thermal insulation (Eq. 6) since heat transfer does not happen on that surface (and the geometry is prolonged in that dimension).

$$
q_{0}=0
$$

The simulation was also performed on a modified geometry with a $20 \mathrm{~mm}$ length and $30 \mathrm{~mm}$ length, resulting in practically the same behaviour of temperature in the centre of the hot-spot; therefore the $10 \mathrm{~mm}$ model was used due to the lower required computational power in all cases.

The mesh was generated and optimized for the different boundaries, resulting in Fig. 3. The mesh was optimized for minimal element count where the results were practically similar with more refined mesh resolution - in order to save computational power (the current element count for Fig. 3 case is 59640).

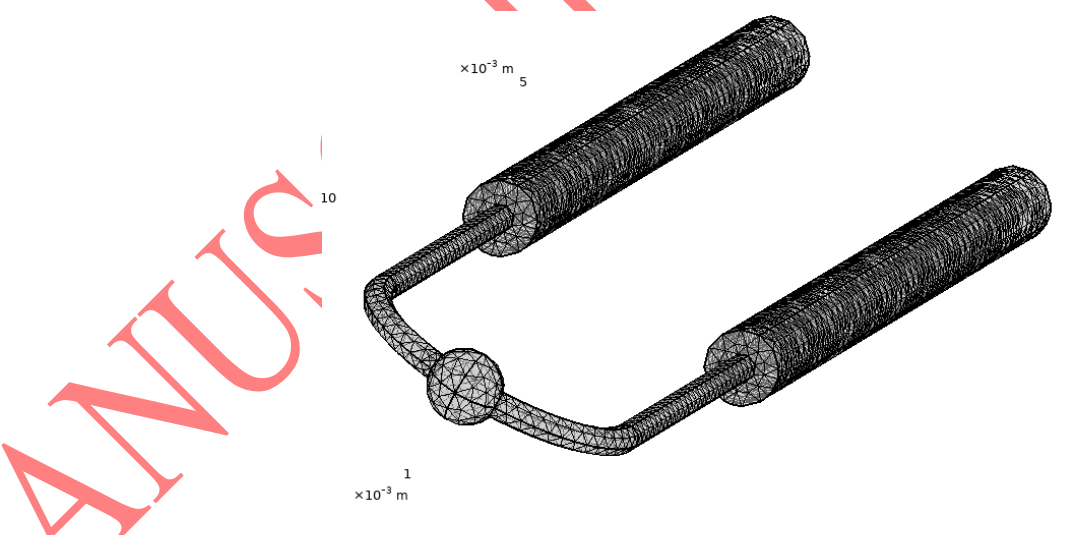

Fig. 3. Mesh example, (400 $\mu \mathrm{m}$ radius hot spot, $400 \mu \mathrm{m}$ radius insulation, $7 \mathrm{~mm}$ insulation length)

\section{VALIDATION MEASUREMENT}

The simulation results were validated by measuring a K-type thermocouple immersed into saturated Galden vapour (Fig. 4). The simulation parameters were set to have similar geometry as the thermocouple used for validation ( $6 \mathrm{~mm}$ insulation length, $270 \mu \mathrm{m}$ hot spot radius, $270 \mu \mathrm{m}$ outer diameter of insulation).

Results show that $175^{\circ} \mathrm{C}$ temperature is reached approximately at the same time. The transient behaviour is different, which can be attributed to the time dependence of the heat transfer coefficient describing the 
condensation and also the immersion to the vapour is not instantaneous. The simulation can be extended in the future by investigating the dynamic behaviour of the heat transfer coefficient.

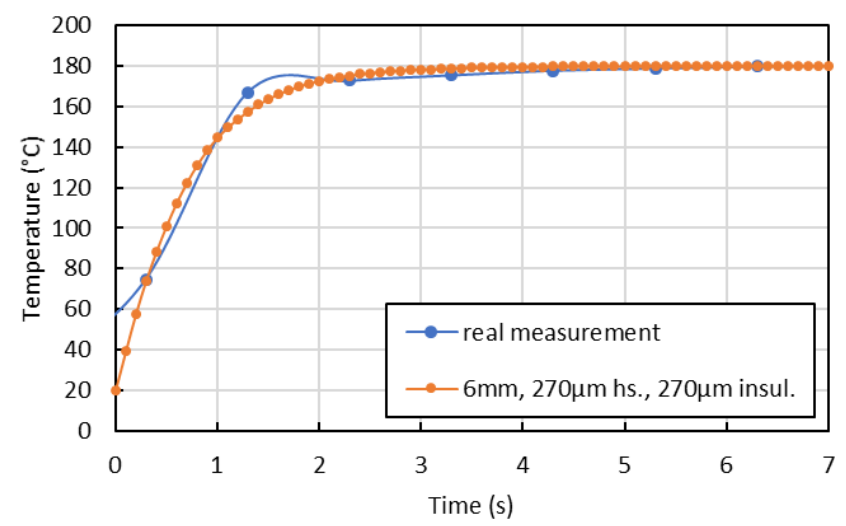

Fig. 4. Comparison of validation measurement

\section{SIMULATION RESULTS}

\subsection{Effect of different insulation lengths}

Fig. 5. shows the surface temperature a selected simulation result after $10 \mathrm{~s}(270 \mu \mathrm{m}$ radius hot spot and insulation, $7 \mathrm{~mm}$ insulation length). However, from the measurement technology point of view, the surface might not give appropriate information regarding the volumetric state of the thermocouple. Therefore, for a more transparent comparison between the simulation cases (Table II.) one point was selected from the geometry: the centre of the hot-spot (which is the most critical point regarding measurement accuracy).

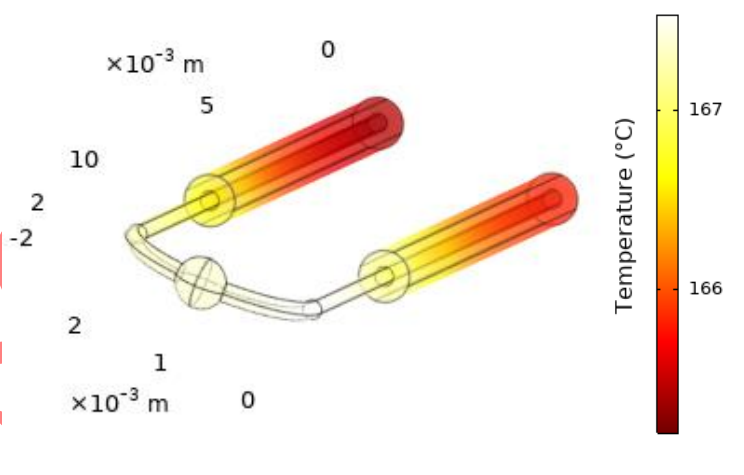

Fig. 5. Simulated surface temperature ( $\mathrm{t}=10 \mathrm{~s}, 270 \mu \mathrm{m}$ radius hot spot and insulation, $7 \mathrm{~mm}$ insulation length)

Each study was set to run for 10 seconds of investigated time window, with a time step of $0.1 \mathrm{~s}$. On Fig. 6. the different insulation lengths (from $2 \mathrm{~mm}$ to $10 \mathrm{~mm}$ ) are presented for $270 \mu \mathrm{m}$ hot-spot (hs.) radius and $270 \mu \mathrm{m}$ insulation outer radius (insul.). 


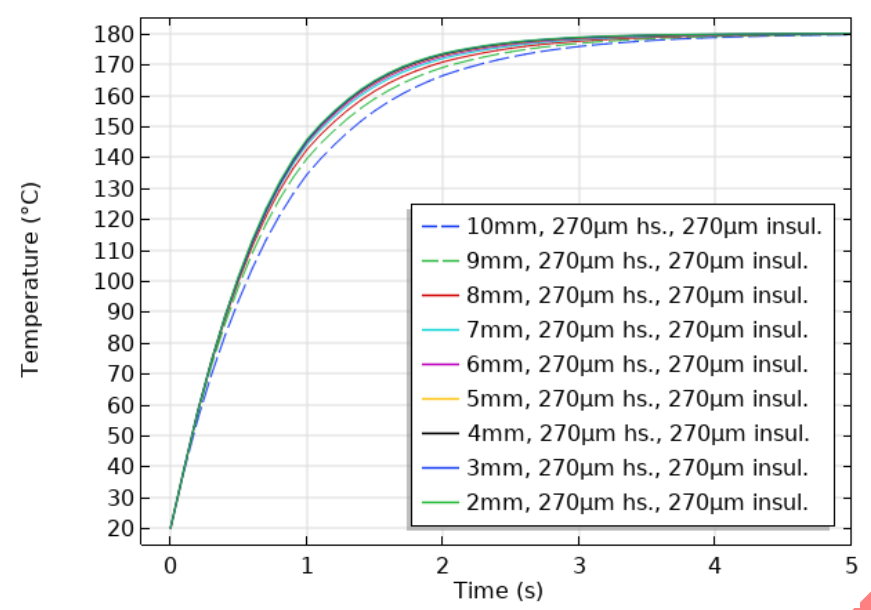

Fig. 6. Effect of different insulation lengths on the hot-spot of the thermocouple

The lower the insulation length results in higher exposed wire length. The simulation results show that the lower the insulation length, the faster the thermal response of the thermocouple is. It can also be seen that the difference between the result is getting closer to each other as the insulation length is reduced.

\subsection{Effect of different hot-spot diameters}

Fig. 7. shows the effect of the difference in the diameter of the hot-spot. For a better overview, only selected cases are illustrated, but the trends apply to all situations.

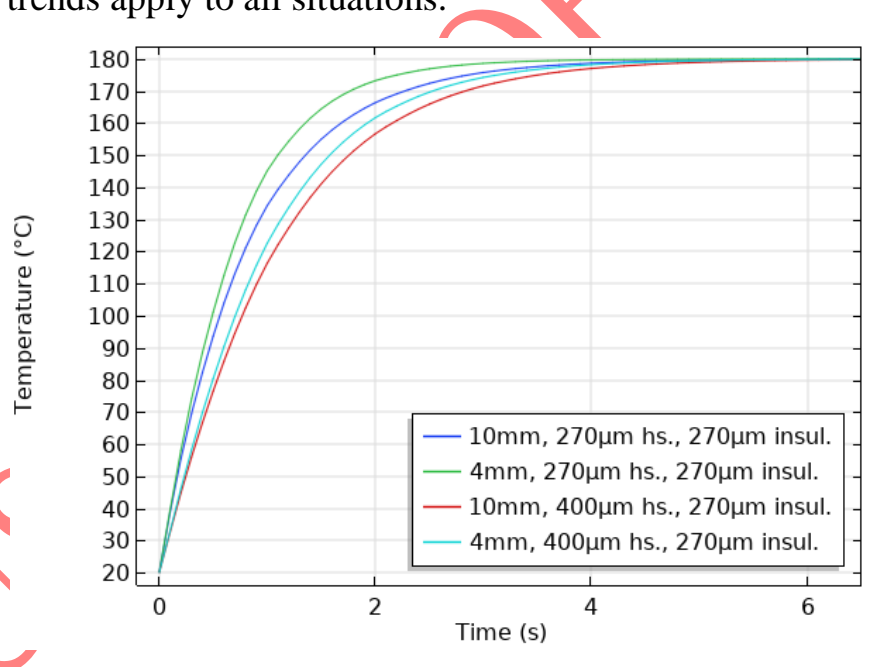

Fig. 7. Comparison of different hot-spot radiuses at different insulation lengths

It can be seen that the higher diameter results in slower temperature response. It is also important to note that the difference between the $10 \mathrm{~mm}$ and the $4 \mathrm{~mm}$ insulation length is lower in case of the higher radius. Those effects are attributed to the higher thermal mass resulting from the thermocouple construction, resulting from the enlarged radius. The effect of possible thermocouple hot spot diameter geometry deviance can be investigated with such a method to evaluate the effect of manufacturing precision on actual measurements.

\subsection{Effect of different insulation thicknesses}

On Fig. 8., the impact of the insulation thickness is illustrated. The hot-spot radius is $270 \mu \mathrm{m}$ in each case, the outer radius of the PFA insulation is compared: $270 \mu \mathrm{m}$ and $400 \mu \mathrm{m}$. 

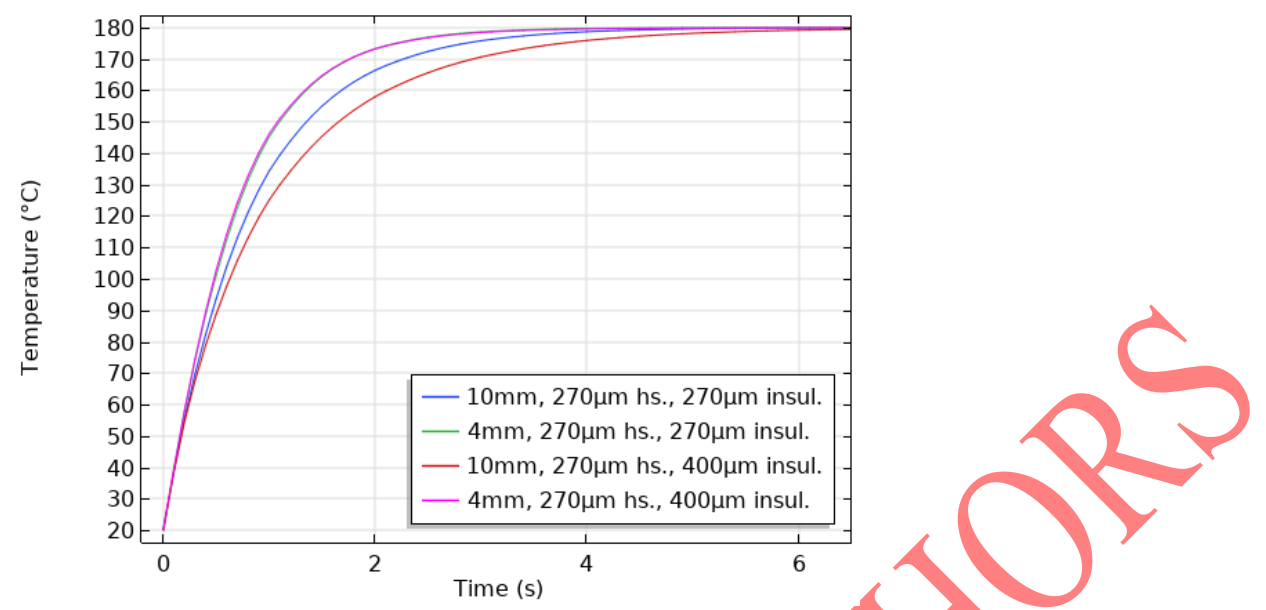

Fig. 8. Comparison of different insulation thicknesses at different insulation lengths

Results show that when the insulation is close to the hot-spot, the alternation attributed to the increased insulation thickness is more significant. However, the longer the uninsulated wire, the less effect the insulation thickness has on the thermal transient of the hot-spot.

\subsection{Effect of different heat transfer coefficient}

Fig. 9. shows the simulation result differences between the previously discussed 60,210 and $420\left[\mathrm{~W} / \mathrm{m}^{2} \mathrm{~K}\right]$ heat transfer coefficients.

As expected, the trends are the same, but the temperature response is slower in case of a lower heat transfer coefficient. It must be noted that the determination of the appropriate heat transfer coefficient to describe a soldering process is a complex task in itself.

It can be said overall, that with the increased heat transfer coefficients of VPS, the amount of deviance originated from the construction is becoming less significant. This shows the possible superiority of VPS processes from the aspect of data aquisition precision with thermocouple measurements, where physical sensor constructions may have deviations on such parameters.

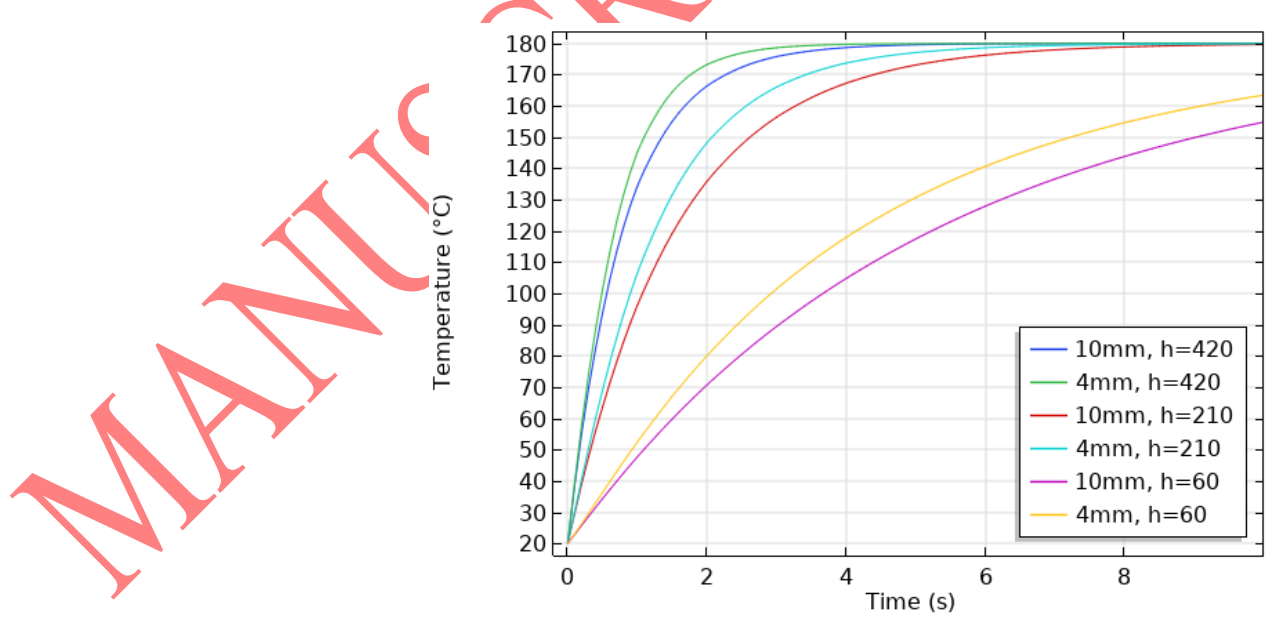

Fig. 9. Comparison of different heat transfer coefficients (h) for different insulation lengths ( $270 \mu \mathrm{m}$ hs., $270 \mu \mathrm{m}$ insul.)

\section{Conclusions}

Finite element simulation was performed on a modelled K-type thermocouple, for different physical construction. The results showed that higher insulation length results in a slower thermal response of the hot-spot 
(Fig. 6). Lower hot-spot radius results in a faster thermal response (Fig. 7). Higher insulation thickness also results in a slower response, but its effect is getting less significant as the insulation length is reduced (Fig. 8). Lower heat transfer coefficient values resulted in lower temperature response while maintaining the same trends (Fig. 9). It can be said that the effect of the insulation length and thickness, and the radius of the hot-spot changes the temperature response of the thermocouple in the same manner in the investigated reflow-soldering relevant heat transfer coefficient range. The validation measurement (Fig. 4) with a thermocouple showed good agreement with the simulation result; however, the transient behaviour needs further investigation.

For future work, we aim to extend investigations for higher temperature Galden, different insulation materials, thermocouple types and constructions. Quantitative analysis will reveal possible timely differences which can be applied (or neglected) in actual PCB assembly reflow temperature monitoring, or in oven programming, from the aspect of refined process control, which is an increasing requirement in the trends of Industry4.0 directives.

\section{ACKNOWLEDGEMENT}

The VPS related research reported in this paper has been supported by the National Research, Development and Innovation Office - NKFIH, FK 132186; the applied sensor related research has been supported by the National Research, Development and Innovation Fund (TUDFO/51757/2019-ITM) Thematic Excellence Program.

\section{REFERENCES}

[1] H. Shaukatullah, and A. Claassen, "Effect of Thermocouple Wire Size and Attachment Method on Measurement of Thermal Characteristics of Electronic Package," Proc. of 19 IEEE Semi-Therm Sym. 2003.

[2] Papaioannou, N., Leach, F., and Davy, M., "Effect of Thermocouple Size on the Measurement of Exhaust Gas Temperature in Internal Combustion Engines," SAE Technical Paper 2018-01-1765, 2018, https://doi.org/10.4271/2018-01-1765.

[3] Noriega, M., Ramírez, R., López, R., Vaca, M., Morales, J., Terres, H., ... Chávez, S. (2015). Thermocouples calibration and analysis of the influence of the length of the sensor coating. Journal of Physics: Conference Series, 582, 012029. doi:10.1088/1742-6596/582/1/012029

[4] www.tcdirect.com, accessed at 2020. 04. 15.

[5] Asscon, Operation Instructions, Quicky 450-2 04.2009. 23-24.

[6] Alaya, M., Megyeri, V., Bušek, D., Harsányi, G. and Geczy, A. (2020), "Effect of different thermocouple constructions on heat-level vapour phase soldering profiles", Soldering \& Surface Mount Technology, Vol. ahead-of-print No. aheadof-print. https://doi.org/10.1108/SSMT-10-2019-0034

[7] www.matweb.com, accessed at April 2020.

[8] Whalley, D. (2004), A simplified reflow soldering process model. Journal of Materials Processing Technology, 150(12), 134-144. doi:10.1016/j.jmatprotec.2004.01.029

[9] Straubinger, D., Bozsóki, I., Illes, B., Krammer, O., Bušek, D. and Geczy, A. (2020), "Heat transfer aspects of condensation during vapour phase soldering on aligned PCB-based surfaces", Soldering \& Surface Mount Technology, Vol. ahead-of-print No. ahead-of-print. https://doi.org/10.1108/SSMT-11-2019-0038

[10] W. Leider, Dampfphasenlöten: Grundlagen und praktische Anwendung, first ed., Eugen G. Leuze Verlag (2002) 